\title{
RESEARCH
}

Open Access

\section{Surgical approach to solid pseudopapillary neoplasms of the proximal pancreas: minimally invasive vs. open}

Emmanuel II Uy Hao ${ }^{1}$ (D), Seoung Yoon Rho 2,3 ${ }^{2, \text { Ho Kyoung Hwang }}{ }^{2,3}$, Jae Uk Chung ${ }^{4}$, Woo Jung Lee ${ }^{2,3}$, Dong Sup Yoon ${ }^{2,5}$ and Chang Moo Kang ${ }^{2,3^{*}}$

\begin{abstract}
Background: Solid pseudopapillary neoplasms (SPN) of the pancreas are rare pancreatic neoplasms where complete resection is the cornerstone in management. It has been demonstrated in previous studies that minimally invasive surgical approaches are effective management options in treating SPNs of the distal pancreas. The purpose of this study is to evaluate the feasibility of minimally invasive surgery in treating SPNs of the uncinate, head, and neck of the pancreas.

Methods: Data from 2005 to 2017 at Severance Hospital of the Yonsei University Health systems in Seoul, South Korea, were retrospectively collected for 25 patients who were diagnosed with SPN of the uncinate, head, and neck of the pancreas and who underwent curative resection. Three groups of patients were considered, depending on the year of surgery, in order to determine trends in the surgical management of SPN. The patients were also divided into two groups corresponding to the type of operation done (minimally invasive surgery vs. open surgery). Perioperative patient data, including age, gender, body mass index (BMI), tumor size, and operation done, were compared and analyzed statistically. Long-term nutritional effects were measured using the Controlling Nutritional Status (CONUT) scoring system.
\end{abstract}

Results: There were no statistically significant differences in age, gender, BMI, symptomatic presentation, operation type, tumor size, and tumor stage between the three time periods. In comparing between minimally invasive and open surgery, there were no statistically significant differences in age, gender, symptomatic presentation, BMI, tumor size, preoperative stage, type of operation, operation time, pancreatic duct size, post-operative pancreatic fistula (POPF) grade, death associated with disease, recurrence, pathological parameters, and change in CONUT score. There was a significant difference in tumor size $(4.5 \pm 1.8$ vs. $2.6 \pm 1.0 \mathrm{~cm}, p=0.004)$, blood loss $(664.2 \pm 512.4$ vs. $277.7 \pm 250.8 \mathrm{~mL}, p=0.024)$, need to transfuse ( $33 \% \mathrm{vs.} 0 \%, p=0.023$ ), hospital length of stay ( $27.4 \pm 15.3 \mathrm{vs}$. $11.5 \pm 5.3$ days, $p=0.002)$, and complication rate ( $75 \%$ vs. $30.8 \%, p=0.027)$ between the two groups.

Conclusions: In appropriately selected patients with SPNs of the uncinate, head, and neck of the pancreas, a minimally invasive surgical approach offers at least equal oncologic and nutritional outcomes, while demonstrating decreased complications and decreased hospital length of stay compared with that of an open surgical approach.

\footnotetext{
* Correspondence: cmkang@yuhs.ac

${ }^{2}$ Division of Hepatobiliary and Pancreatic Surgery, Department of Surgery,

Yonsei University College of Medicine, Seoul, South Korea

${ }^{3}$ Pancreatobiliary Cancer Center, Yonsei Cancer Center, Severance Hospital,

Seoul, South Korea

Full list of author information is available at the end of the article
}

(c) The Author(s). 2019 Open Access This article is distributed under the terms of the Creative Commons Attribution 4.0 International License (http://creativecommons.org/licenses/by/4.0/), which permits unrestricted use, distribution, and reproduction in any medium, provided you give appropriate credit to the original author(s) and the source, provide a link to the Creative Commons license, and indicate if changes were made. The Creative Commons Public Domain Dedication waiver (http://creativecommons.org/publicdomain/zero/1.0/) applies to the data made available in this article, unless otherwise stated. 


\section{Background}

Neoplasms of the pancreas are the fourth most common cause of cancer-related death globally [1]. These tumors are often difficult to detect due to their location; most patients present with non-specific symptoms or clinicians discover them on incidental radiographs for different conditions [2, 3]. Solid pseudopapillary neoplasm (SPN) of the pancreas, also referred to as Frantz's tumor, is rare, comprising $1-2 \%$ of all pancreatic tumors [4-6]. SPNs of the pancreas are usually diagnosed in females who are in their third to fourth decade of life and this tumor carries a good prognosis, with a 5year survival rate of up to 97\% [6-9]. SPN is considered to be a tumor with low malignant potential; however, up to $10-15 \%$ of cases have been reported to be aggressive and can metastasize to the liver and/or peritoneum [10]. Despite its malignant potential, resections with no microscopically detected cancer cell at the resection margin (R0) and en bloc resections have been reported to improve overall survival and disease-free survival $[11,12]$.

The distal pancreas is the most common site of occurrence, but with advancements in imaging techniques and practices, SPNs located at the uncinate, head, and neck of the pancreas, referred collectively henceforth as the proximal pancreas, are now being increasingly reported $[9,13]$. A previous study compared the outcomes of minimally invasive (MI) and open distal pancreatectomies in patients with SPN where the outcome favored minimally invasive surgical approaches (laparoscopic and robot-assisted) [14]. As such, the need to investigate surgical approaches for SPNs of the proximal pancreas is needed in order to provide the surgeon with viable options in the management of all SPNs of the pancreas.

Therefore, the purpose of this study was to compare the perioperative short-term and long-term outcomes of minimally invasive (laparoscopic and robotic) and open surgical approaches of the proximal pancreas in patients with pathologically confirmed SPNs.

\section{Methods}

\section{Data collection}

Patients' medical records were retrospectively reviewed to identify those who underwent either open or MI pylorus-preserving pancreaticoduodenectomy (PPPD), classic Whipple procedure (PD), or central pancreatectomy (CP) for pathologically confirmed SPNs between 2006 and 2017 at the Severance Hospital of the Yonsei University Health System in Seoul, South Korea. Data representing the clinicopathological characteristics, such as age, gender, tumor size, and location, were retrospectively collected. Patients who underwent extensive surgeries or combined resections were excluded from this study in order to avoid selection bias in the comparative analysis between MI and open surgical approaches.

For the assessment of long-term nutrition, the Controlling Nutritional Status (CONUT) scoring system was used. The CONUT score utilizes serum albumin, cholesterol, and total lymphocyte count as parameters to measure the nutritional status of patients and has been shown to be predictive of survival in colorectal neoplasms $[15,16]$ and hepatocellular neoplasms [17]. We stratified the study population into three groups according to the year when the surgery was performed (e.g., 2006-2009, 2010-2013, 2014-2017) to determine the chronological trends of clinical characteristics in patients with SPNs. This study protocol was approved by the local institutional review board, with the IRB number 42018-0001.

\section{Statistical analysis}

IBM SPSS Statistics, version 23 (SPSS Inc., Chicago, IL, USA) was used for the statistical analyses. Continuous variables were presented as mean \pm standard deviation and categorical variables were represented as percentage or frequency. Student's $t$ test was performed to compare the continuous variables, and Fisher's exact test or the chi-squared test was used to compare categorical data between approaches.

\section{Results}

Chronological changes of clinical characteristics according to period

From 2006 to 2017, 98 patients underwent surgery for SPN at the Severance Hospital of the Yonsei University Health Systems. Of the 98 patients, 25 were diagnosed with SPN at the proximal pancreas and were included in this study. There were no statistical differences in the age, gender, BMI, and symptoms across the three periods (Table 1). There was an increasing trend of patients undergoing minimally invasive procedures from the first time period up to the third time period; however, this was not statistically significant $(p=0.269)$. Moreover, the neoplasm stage at presentation was not statistically significant; however, it was noted that the size of tumors was smaller during the period from 2014 to 2017 compared to the period from 2010 to 2013.

\section{General patient characteristics}

Of the 25 patients included in this study, 22 were female and three were male (female to male ratio was $7.3: 1$ ). On average, the patients were $38.2 \pm 14.3$ years old and had a BMI of $22.4 \pm 2.58 \mathrm{~kg} / \mathrm{m}^{2}$. Additionally, the mean tumor size was $3.51 \pm 1.72 \mathrm{~cm}$ with a mean 
Table 1 Summary of data per time period

\begin{tabular}{|c|c|c|c|c|}
\hline & 2006-2009 & 2010-2013 & 2014-2017 & $p$ value \\
\hline Number & 7 & 11 & 7 & \\
\hline Age (years) & $39.43 \pm 12.78$ & $35.91 \pm 15.42$ & $40.71 \pm 15.55$ & 0.775 \\
\hline Gender (F:M) & $7: 0$ & $9: 2$ & $6: 1$ & 0.500 \\
\hline BMI $\left(\mathrm{kg} / \mathrm{m}^{2}\right)$ & $21.71 \pm 2.87$ & $22.82 \pm 2.36$ & $22.43 \pm 2.88$ & 0.694 \\
\hline $\begin{array}{l}\text { Symptomatic } \\
\text { (yes/no) }\end{array}$ & $2 / 5$ & $5 / 6$ & $2 / 5$ & 0.997 \\
\hline $\begin{array}{l}\text { Operation type } \\
\text { (Ml/open) }\end{array}$ & $2 / 5$ & $5 / 6$ & $5 / 2$ & 0.269 \\
\hline $\begin{array}{l}\text { Operation } \\
\text { (PPPD/CP) }\end{array}$ & $3 / 4$ & $8 / 3$ & $5 / 2$ & 0.389 \\
\hline Tumor size $(\mathrm{cm})$ & $3.63 \pm 1.91$ & $4.12 \pm 1.82$ & $2.44 \pm 0.78^{*}$ & 0.126 \\
\hline Stage & & & & 0.833 \\
\hline la & $2(28 \%)$ & 2 & $2(28 \%)$ & \\
\hline $\mathrm{lb}$ & $5(72 \%)$ & 9 & $5(72 \%)$ & \\
\hline
\end{tabular}

Data are presented as number, mean \pm standard deviation, or number (percentage)

$F$ female, $M$ male, $B M I$ body mass index, $M I$ minimally invasive, $P P P D$ pylorus preserving pancreaticoduodenectomy, $C P$ central pancreatectomy

*There was a statistically significant $(p=0.017)$ decrease in tumor size noted between periods 2010-2013 and 2014-2017

Table 2 Perioperative comparison between minimally invasive and open surgeries

\begin{tabular}{|c|c|c|c|}
\hline & Minimally invasive $(n=13)$ & Open $(n=12)$ & $p$ value \\
\hline Age (years) & $41.0 \pm 13.5$ & $35.3 \pm 15.4$ & 0.326 \\
\hline Gender (F:M) & $11: 2$ & $11: 1$ & 0.588 \\
\hline $\begin{array}{l}\text { Symptomatic } \\
\text { (yes/no) }\end{array}$ & $3 / 10$ & $6 / 6$ & 0.161 \\
\hline BMI $\left(\mathrm{kg} / \mathrm{m}^{2}\right)$ & $22.8 \pm 2.6$ & $21.9 \pm 2.5$ & 0.380 \\
\hline Tumor size $(\mathrm{cm})$ & $2.6 \pm 1.0$ & $4.5 \pm 1.8$ & $0.004^{*}$ \\
\hline Preoperative stage & & & 0.645 \\
\hline la & $4(30.8 \%)$ & $2(16.7 \%)$ & \\
\hline $\mathrm{lb}$ & $9(69.2 \%)$ & $10(83.3 \%)$ & \\
\hline Operation & & & 0.411 \\
\hline PPPD & $7(53.8 \%)$ & $9(75 \%)$ & \\
\hline $\mathrm{CP}$ & $6(46.2 \%)$ & $3(25 \%)$ & \\
\hline OR time (min) & $417.2 \pm 115.6$ & $413.9 \pm 132.4$ & 0.949 \\
\hline Blood loss (mL) & $277.7 \pm 250.8$ & $664.2 \pm 512.4$ & $0.024^{*}$ \\
\hline $\begin{array}{l}\text { Need for transfusion } \\
\text { (yes/no) }\end{array}$ & $0 / 13$ & $4 / 8$ & $0.023^{*}$ \\
\hline $\begin{array}{l}\text { Pancreas description } \\
\text { (soft/hard) }\end{array}$ & $13 / 0$ & $12 / 0$ & \\
\hline $\begin{array}{l}\text { Pancreatic duct } \\
\text { size }(\mathrm{mm})\end{array}$ & $1.15 \pm 0.83$ & $1.43 \pm 1.2$ & 0.496 \\
\hline Resection type & All RO & All RO & \\
\hline $\begin{array}{l}\text { Hospital length } \\
\text { of stay (days) }\end{array}$ & $11.5 \pm 5.3$ & $27.4 \pm 15.3$ & $0.002^{*}$ \\
\hline Complication incidence & $4(30.8 \%)$ & $9(75 \%)$ & $0.027^{*}$ \\
\hline POPF (grade A/grade B) & $2(15.4 \%) / 2(15.4 \%)$ & $3(25 \%) / 1(8.33 \%)$ & 0.465 \\
\hline
\end{tabular}

Data are presented as number, mean \pm standard deviation, or number (percentage)

$F$ female, $M$ male, $B M I$ body mass index, $P P P D$ pylorus preserving pancreaticoduodenectomy, $C P$ central pancreatectomy, $O R$ operating room, $R O$ no microscopically detected cancer cells at the resection margin, $P O P F$ post-operative pancreatic fistula.

* Statistically significant difference between surgical approaches at $p<0.05$ 
pancreatic duct size of $1.29 \pm 1.00 \mathrm{~mm}$. Nine of the patients presented with symptoms associated with the tumor, while the tumor was an incidental finding in the remaining 16 patients. Six (24\%) patients presented as stage Ia and 19 (76\%) as stage Ib. Twelve patients underwent an open surgical procedure and 13 underwent a minimally invasive surgical procedure, two of which underwent robotic surgery. Nine patients underwent $\mathrm{CP}$ and 16 underwent PPPD. There were no reported cases of patients who underwent PD. The patients were followed up for an average of $48.0 \pm 31.9$ months.

\section{Comparative analysis between $\mathrm{MI}$ and open surgical approaches for SPN of the proximal pancreas}

There were no statistically significant differences between patients who underwent open versus patients who underwent MI surgeries in terms of age, gender, symptomatic presentation, BMI, preoperative stage, type of operation, operation time, pancreatic duct size, and post-operative pancreatic fistula (POPF) grade $(p>0.05$ for all; Table 2). All patients underwent an R0 resection and all remnant pancreata were described to be soft on palpation. In contrast, tumor size, blood loss, need for transfusion, hospital length of stay, and complication incidence were significantly greater in open surgery compared to MI surgery ( $p \leq 0.027$ for all).

\section{Histopathologic outcomes}

We compared the histopathologic outcomes of the patients based on their surgical approach. The collected data is presented in Table 3. During the follow-up period (median, 57 months; range, 4-120 months), none of the patients in this study experienced tumor recurrence or death as a result of the disease. All pathologic resection margins were negative for disease. Further, a review of the microscopic pathologic parameters (capsular invasion, lymphovascular invasion, perineural invasion), as well as the post-operative stage, revealed that there were no significant differences between the surgical approaches.

\section{Long-term nutritional assessment}

The CONUT scoring system was used to determine the nutritional status of patients prior to surgery and 6 and 12 months after surgery. Nearly all of the patients had improvements, and none experienced worsening, in nutritional status (Table 4). No significant changes in nutritional status were detected between the surgical approaches at 6 and 12 months after surgery $(p>0.05$ for all, Table 4).

\section{Discussion}

In a previous study, we have reported the surgical outcomes of minimally invasive distal pancreatectomy for SPN of the pancreas [14]. There are also several literatures reported [18-22] showing favorable perioperative outcomes in managing SPN of the distal pancreas; however, minimally invasive surgical procedures (PPPD or $\mathrm{CP}$ ) for SPN in the proximal pancreas seems rare.

Patients who underwent open or MI surgeries for SPN at the proximal pancreas showed no statistically significant differences in terms of gender, age, BMI, pancreas characteristics, operation time, and American Joint Committee on Cancer (AJCC) cancer stage. However, it was demonstrated that patients with MI surgery had a smaller tumor size at presentation (mean, 2.6 vs. $4.5 \mathrm{~cm}$, respectively), which may have been a factor in deciding which surgical approach to perform in managing SPN of the proximal pancreas.

The study results showed statistically significant differences in length of hospital stay, complication incidence, blood loss, and transfusion requirement, all of which favored the MI surgical approach. These

Table 3 Histopathologic outcomes of minimally invasive and open surgeries

\begin{tabular}{|c|c|c|c|}
\hline & Minimally invasive $(n=13)$ & Open $(n=12)$ & $p$ value \\
\hline $\begin{array}{l}\text { Death associated } \\
\text { with disease }\end{array}$ & None & None & \\
\hline Recurrence & None & None & \\
\hline Resection margin & All negative & All negative & \\
\hline Capsular invasion & $3(23.1 \%)$ & $2(16.7 \%)$ & 0.698 \\
\hline Lymphovascular invasion & $1(7.69 \%)$ & 0 & 0.327 \\
\hline Perineural invasion & $3(23.1 \%)$ & $2(16.7 \%)$ & 0.689 \\
\hline Stage & & & 0.409 \\
\hline la & $4(30.8 \%)$ & $1(8.33 \%)$ & \\
\hline $\mathrm{lb}$ & $6(46.2 \%)$ & $9(75 \%)$ & \\
\hline$\| a$ & $3(23.1 \%)$ & $2(16.7 \%)$ & \\
\hline
\end{tabular}

Data are presented as number (percentage) 
Table 4 Changes in CONUT score of patients undergoing surgery of the proximal pancreas

\begin{tabular}{|c|c|c|c|c|c|c|}
\hline \multirow[t]{2}{*}{$\begin{array}{l}\text { CONUT score for } \\
\text { severity of malnutrition }\end{array}$} & \multicolumn{2}{|l|}{$\begin{array}{l}\text { Pre-operative } \\
n(\%)\end{array}$} & \multicolumn{2}{|l|}{$\begin{array}{l}6 \text { months } \\
\text { post-operative } \\
n(\%)\end{array}$} & \multicolumn{2}{|l|}{$\begin{array}{l}12 \text { months } \\
\text { post-operative } \\
n(\%)\end{array}$} \\
\hline & $\begin{array}{l}\text { Minimally invasive } \\
(n=13)\end{array}$ & $\begin{array}{l}\text { Open } \\
(n=12)\end{array}$ & $\begin{array}{l}\text { Minimally invasive } \\
(n=13)\end{array}$ & $\begin{array}{l}\text { Open } \\
(n=12)\end{array}$ & $\begin{array}{l}\text { Minimally invasive } \\
(n=13)\end{array}$ & $\begin{array}{l}\text { Open } \\
(n=12)\end{array}$ \\
\hline Normal (without deficit) & 0 & 0 & $9(69 \%)$ & $9(75 \%)$ & $11(85 \%)$ & $10(83 \%)$ \\
\hline Mild & $7(54 \%)$ & $4(33 \%)$ & $4(31 \%)$ & $3(25 \%)$ & $2(15 \%)$ & $2(17 \%)$ \\
\hline Moderate & $5(38 \%)$ & $6(50 \%)$ & 0 & 0 & 0 & 0 \\
\hline Severe & $1(8 \%)$ & $2(17 \%)$ & 0 & 0 & 0 & 0 \\
\hline
\end{tabular}

CONUT Controlling Nutritional Status

parameters are often used when comparing surgical procedures and their possible adverse effects on patients. Needless to say, shorter hospital stay, decreased blood loss, and lower need for transfusion are all positive aspects that advocate for the recommendation of MI surgery in selected patients with SPN of the proximal pancreas. These findings coincide with those of Torres et al. who reported a successful laparoscopic pancreaticoduodenectomy in a 19/F with SPN who was discharged after 6 days without complication [23]. Similarly, Senthilnathan et al. reported five successful laparoscopic pancreaticoduodenectomy operations in their 8-year experience [24].

It should also be noted that there was no residual tumor after the operation and that all pathological reports indicated margin-free tumors in all cases. This entails that both open and MI surgical approaches can deliver comparable long-term results that are within the oncologic parameters.

The role of nutrition in improving perioperative outcomes is being recognized increasingly. Several researches describe decreased complications, as well as improved surgical outcomes, as a direct effect of improving the perioperative nutritional status of the patient [25-28]. Our study noted that there was an improvement in the CONUT score of nearly all of the patients at 6 and 12 months after surgery. However, there was no statistical difference in the change of nutritional status between the surgical approaches $(p<0.05)$. This implies that both open and MI surgical approaches can achieve quality of life goals in managing patients with SPN.

\section{Conclusion}

The current first-line treatment for SPN of the pancreas remains to be complete excision. Studies have shown that complete excision can increase overall survival and disease-free survival. However, as with all surgical encounters, we must balance these maximal oncologic practices with minimizing complications and potential adverse outcomes. This study suggests that in appropriately selected patients with SPNs located at the uncinate, head, or neck of the pancreas, a MI surgical approach offers at least comparable oncologic outcomes as an open approach, while demonstrating decreased complications and decreased hospital length of stay. We recommend that a larger comparison be conducted in order to strengthen this conclusion.

\section{Abbreviations}

AJCC: American Joint Committee on Cancer; BMl: body mass index

CONUT: Controlling Nutritional Status; CP: central pancreatectomy; F: female; IRB: Institutional Review Board; M: male; MI: minimally invasive; OR: operating room; PD: Whipple's procedure; POPF: post-operative pancreatic fistula; PPPD: pylorus-preserving pancreaticoduodenectomy; RO: surgical resection with no microscopically detected cancer cells at the resection margin;

SPN: solid pseudopapillary neoplasm

\section{Acknowledgements}

Not applicable

Authors' contributions

EUH-II contributed to the research design, data collection, data analysis, and manuscript writing. SYR contributed to the data collection and manuscript writing. $\mathrm{HKH}$ contributed to the data analysis and manuscript editing. JUC contributed to the data collection and manuscript editing. WJL contributed to the research design, data analysis, and final approval of manuscript. DSY contributed to the research design, data analysis, and final approval of manuscript. CMK contributed to the research design, data analysis, and final approval of manuscript. All authors read and approved the final manuscript.

Funding

This study was not funded.

Availability of data and materials

The datasets used and/or analyzed during the current study are available from the corresponding author on reasonable request.

Ethics approval and consent to participate

This article does not contain any studies with human participants performed by any of the authors, pursuant to the guidelines of the local institutional review board, with the IRB approval number 4-2018-0001.

Consent for publication

Not applicable

Competing interests

The authors declare that they have no competing interests.

\section{Author details}

'Department of Surgery, University of the Philippines-Philippine General Hospital, Taft Avenue, Manila, Philippines. ${ }^{2}$ Division of Hepatobiliary and Pancreatic Surgery, Department of Surgery, Yonsei University College of Medicine, Seoul, South Korea. ${ }^{3}$ Pancreatobiliary Cancer Center, Yonsei Cancer 
Center, Severance Hospital, Seoul, South Korea. ${ }^{4}$ Department of Surgery, National Health Insurance Service Ilsan Hospital, Goyang, South Korea. ${ }^{5}$ Pancreatobiliary Cancer Clinic, Department of Surgery, Gangnam Severance Hospital, Yonsei University College of Medicine, Seoul, Korea.

Received: 17 May 2019 Accepted: 30 July 2019

Published online: 12 September 2019

\section{References}

1. Pelosi E, Castelli G, Testa U. Pancreatic cancer: molecular characterization, clonal evolution and cancer stem cells. Biomedicines. 2017;5(4).

2. Alexandrescu DT, O'Boyle K, Feliz A, Fueg A, Wiernik PH. Metastatic solidpseudopapillary tumour of the pancreas: clinico-biological correlates and management. Clin Oncol (R Coll Radiol). 2005;17(5):358-63.

3. Coleman KM, Doherty MC, Bigler SA. Solid-pseudopapillary tumor of the pancreas. Radiographics. 2003;23(6):1644-8.

4. Watanabe Y, Okamoto K, Okada K, Aikawa M, Koyama I, Yamaguchi H. A case of aggressive solid pseudopapillary neoplasm: comparison of clinical and pathologic features with non-aggressive cases. Pathol Int. 2017;67(4):202-7.

5. Martin RC, Klimstra DS, Brennan MF, Conlon KC. Solid-pseudopapillary tumor of the pancreas: a surgical enigma? Ann Surg Oncol. 2002;9(1):35-40.

6. Bhutani N, Kajal P, Singla S, Sangwan V. Solid pseudopapillary tumor of the pancreas: experience at a tertiary care centre of Northern India. Int J Surg Case Rep. 2017:39:225-30.

7. Papavramidis T, Papavramidis S. Solid pseudopapillary tumors of the pancreas: review of 718 patients reported in English literature. J Am Coll Surg. 2005;200(6):965-72.

8. Klimstra DS, Wenig BM, Heffess CS. Solid-pseudopapillary tumor of the pancreas: a typically cystic carcinoma of low malignant potential. Semin Diagn Pathol. 2000;17(1):66-80.

9. Luttges J. What's new? The 2010 WHO classification for tumours of the pancreas. Pathologe. 2011;32(Suppl 2):332-6.

10. Kang CM, Kim KS, Choi JS, Kim H, Lee WJ, Kim BR. Solid pseudopapillary tumor of the pancreas suggesting malignant potential. Pancreas. 2006;32(3):276-80.

11. Kim JH, Lee JM. Clinicopathologic review of 31 cases of solid pseudopapillary pancreatic tumors: can we use the scoring system of microscopic features for suggesting clinically malignant potential? Am Surg. 2016;82(4):308-13.

12. Law JK, Ahmed A, Singh VK, Akshintala VS, Olson MT, Raman SP, et al. A systematic review of solid-pseudopapillary neoplasms: are these rare lesions? Pancreas. 2014;43(3):331-7.

13. Santini D, Poli F, Lega S. Solid-papillary tumors of the pancreas: histopathology. Jop. 2006;7(1):131-6.

14. Kang CM, Choi SH, Hwang HK, Lee WJ, Chi HS. Minimally invasive (laparoscopic and robot-assisted) approach for solid pseudopapillary tumor of the distal pancreas: a single-center experience. J Hepatobiliary Pancreat Sci. 2011;18(1):87-93.

15. Tokunaga R, Sakamoto $Y$, Nakagawa S, Ohuchi M, Izumi D, Kosumi K, et al. CONUT: a novel independent predictive score for colorectal cancer patients undergoing potentially curative resection. Int J Colorectal Dis. 2017;32(1):99-106.

16. Iseki Y, Shibutani M, Maeda K, Nagahara H, Ohtani H, Sugano K, et al. Impact of the preoperative Controlling Nutritional Status (CONUT) score on the survival after curative surgery for colorectal cancer. PLoS One. 2015;10(7):e0132488.

17. Harimoto N, Yoshizumi T, Sakata K, Nagatsu A, Motomura T, Itoh S, et al. Prognostic significance of preoperative Controlling Nutritional Status (CONUT) score in patients undergoing hepatic resection for hepatocellular carcinoma. World J Surg. 2017:41(11):2805-12.

18. Cai Y, Peng B, Mai G, Ke N, Liu X. Laparoscopic distal pancreatectomy for solid-pseudopapillary tumor of the pancreas. Surg Laparosc Endosc Percutan Tech. 2015;25(1):e8-e10.

19. Zhang RC, Yan JF, Xu XW, Chen K, Ajoodhea H, Mou YP. Laparoscopic vs open distal pancreatectomy for solid pseudopapillary tumor of the pancreas. World J Gastroenterol. 2013;19(37):6272-7.

20. Hori T, Masui T, Kaido T, Ogawa K, Yasuchika K, Yagi S, et al. Laparoscopic distal pancreatectomy with or without preservation of the spleen for solid pseudopapillary neoplasm. Case Rep Surg. 2015;2015:487639.

21. Kanchana WG, Shaminda RA, Galketiya KB, Pinto V, Walisinghe D, Wijetunge $\mathrm{S}$, et al. Laparoscopic resection of pancreatic tail solid pseudopapillary tumour in a young male. Case Rep Gastrointest Med. 2016;2016:4037618.

22. Nakamura Y, Matsushita A, Katsuno A, Yamahatsu K, Sumiyoshi H, Mizuguchi $Y$, et al. Clinical outcomes for 14 consecutive patients with solid pseudopapillary neoplasms who underwent laparoscopic distal pancreatectomy. Asian J Endosc Surg. 2016;9(1):32-6.

23. Torres OJ, Moraes Junior JM, Moraes AM, Torres CC, Oliveira AT. Performance of laparoscopic pancreatoduodenectomy for solid pseudopapillary tumor of pancreas. Am J Case Rep. 2016;17:894-8.

24. Senthilnathan P, Dhaker KC, Kaje V, Naidu SB, Sarvani M, Sabnis SC, et al. Laparoscopic management of solid pseudo papillary neoplasm of pancreas in tertiary care center from south India. Pancreatology. 2017;17(6):927-30.

25. Byrnes A, Banks M, Mudge A, Young A, Bauer J. Enhanced recovery after surgery as an auditing framework for identifying improvements to perioperative nutrition care of older surgical patients. Eur J Clin Nutr. 2018;72(6):913-6.

26. Larson DW, Lovely JK, Welsh J, Annaberdyev S, Coffey C, Corning C, et al. A collaborative for implementation of an evidence-based clinical pathway for enhanced recovery in colon and rectal surgery in an affiliated network of healthcare organizations. Jt Comm J Qual Patient Saf. 2018;44(4):204-11.

27. Qi S, Chen G, Cao P, Hu J, He G, Luo J, et al. Safety and efficacy of enhanced recovery after surgery (ERAS) programs in patients undergoing hepatectomy: a prospective randomized controlled trial. J Clin Lab Anal. 2018:e22434.

28. King AB, Spann MD, Jablonski P, Wanderer JP, Sandberg WS, McEvoy MD. An enhanced recovery program for bariatric surgical patients significantly reduces perioperative opioid consumption and postoperative nausea. Surg Obes Relat Dis. 2018;14(6):849-56.

\section{Publisher's Note}

Springer Nature remains neutral with regard to jurisdictional claims in published maps and institutional affiliations.

\section{Ready to submit your research? Choose BMC and benefit from:}

- fast, convenient online submission

- thorough peer review by experienced researchers in your field

- rapid publication on acceptance

- support for research data, including large and complex data types

- gold Open Access which fosters wider collaboration and increased citations

- maximum visibility for your research: over $100 \mathrm{M}$ website views per year

At BMC, research is always in progress.

Learn more biomedcentral.com/submissions 